\title{
A Justiça Intergeracional e A Metáfora do REFÚGIO DE MONTANHA
}

\author{
Axel Gosseries ${ }^{1}$ \\ (Fonds de la Recherche Scientifique (Bélgica) \& \\ Université Catholique de Louvain)
}

\section{Introdução}

Qualquer teoria de justiça intergeracional tem de responder às duas questões seguintes: "o que devemos às gerações posteriores e anteriores?" e "por que motivo lhes devemos alguma coisa?". Para o fazer, podemos basear-nos nas teorias de justiça convencionais, como o igualitarismo, o libertarianismo, o utilitarismo ou o suficientarianismo ${ }^{2}$. Mostrar o contraste entre as regras gerais defendidas por cada uma destas teorias revela diferenças interessantes e por vezes inesperadas ${ }^{3}$. No presente artigo pretendemos conduzir o leitor por um outro caminho, o de uma metáfora.

$\mathrm{Na}$ esfera intergeracional, várias metáforas visam esclarecer a natureza das relações e obrigações entre gerações. Algumas são de natureza

${ }^{1}$ Agradeço a L. Beckman, C. Bertram, C. Bertram, V. Blondel, A. Cappelen, L. Collès, D. Cosandey, L. de Briey, C. Fabre, Cl. Greed, D. Heyd, B. Hooker, A. Marciano, L. Meyer, N. Perez, J. Thompson, D. Vanderburgh, Ph. Van Parijs bem como a dois revisores anónimos os comentários feitos a uma primeira versão deste texto. Todos os restantes erros são pois do autor. Um agradecimento especial aos meus alunos de St. Louis (Bruxelas). Durante uma aula interactiva em 2001 sobre a justiça intergeracional, dois grupos de estudantes produziram de forma independente a "metáfora do hotel" e o "princípio da casa de banho". Isto despertou a minha curiosidade e levou-me a investigar as metáforas intergeracionais. No tema da justiça intergeracional, dois autores baseiam-se numa metáfora similar à aqui apresentada: Masson (1999: 83 nota 14) (casa de banho pública) e Gardiner (2009: 107) (acampamento). A realização deste artigo contou com o apoio da subvenção da UE XXX bem como do financiamento do Projecto ARC "sustainability" (09/14-018) (Bélgica, Comunidade Francófona).

2 Ver por exemplo Gosseries (2008a); Gosseries \& Meyer (2009).

${ }^{3}$ Gosseries (2008a).

Philosophica, 38, Lisboa, 2011, pp. 121-141 
legal. Consideremos por exemplo a famosa frase: "Não herdamos a Terra dos nossos antepassados; pedimo-la emprestada aos nossos filhos". Comparemo-la com a visão de Jefferson, expressa numa carta a James Madison e datada de 6 de Setembro de 1789, segundo a qual "a terra pertence em usufruto aos vivos". Contrastemo-la com a ideia redigida um século depois por Jaurès (1902), que refere uma "hipoteca eterna". Estes são apenas três exemplos de conceitos legais que nos são relativamente familiares e que visam demonstrar a natureza das nossas obrigações intergeracionais. Um cuidadoso estudo de tais metáforas legais revelaria sem dúvida interessantes propriedades.

Metáforas não-legais também foram propostas. Platão em As Leis (1997: 6. 676b) utiliza a ideia de uma corrida de revezamento da tocha. Hume (1777: 318-319) e Burke (1790: §162) basearam-se ambos em metáforas entomológicas para se referirem à esfera intergeracional e para enfatizar a continuidade das sociedades humanas. A ideia aqui é contrastar a longa duração da vida dos seres humanos e a sobreposição tornada assim possível, face à brevidade da existência de alguns insectos, especialmente no caso dos insectos adultos da ordem dos efemerópteros. É igualmente a Burke (1790: §162) que devemos a referência a uma cadeia, ideia usada mais tarde para designar a cadeia de obrigações entre as gerações. ${ }^{4}$ Corrida de revezamento de gerações, borboletas ou efemerópteros, ligações em cadeia... Cada uma destas metáforas visa apreender uma ou outra especificidade do contexto intergeracional. Aqui, iremos substituir os corredores de revezamento por montanhistas e analisar o nosso planeta por um momento não como um barco salva-vidas mas como um refúgio de montanha no qual aqueles que praticam montanhismo em áreas remotas podem descansar, cozinhar e aquecer-se.

\section{Regras de Refúgio e suas características}

O que é interessante nas vagas de montanhistas é o facto de se sucederem umas às outras, sem que tenham necessariamente a oportunidade de se conhecerem ou encontrarem ${ }^{5}$. Sem dúvida, as gerações diferem dos montanhistas na medida em que apenas estes têm a oportunidade de mais

\footnotetext{
${ }^{4}$ Howarth (1992).

${ }^{5}$ Não pretendo negar, naturalmente, a sobreposição de gerações. Regressaremos mais tarde à importância deste ponto (secção 2.1). Notemos contudo que a sobreposição está sempre limitada a algumas gerações e que colocamos demasiada esperança na capacidade da sobreposição de gerações de tornar um cenário intergeracional similar a um cenário intrageracional. Uma forma de testar as implicações da sobreposição consistiria, como sugerido por um dos revisores, em imaginar um refúgio constantemente ocupado por sucessivos montanhistas, alguns dos quais encontrando-se.
} 
tarde regressar ao refúgio, assim exibindo potencialmente características de um jogo repetido, ausentes do cenário intergeracional. ${ }^{6}$ Contudo, o que é aqui relevante é que o abrigo é um espaço de passagem, tal como o são as cabines telefónicas, as salas de espera dos aeroportos ou as casas de banho públicas. O que é igualmente específico é que os refúgios de montanha não têm um guarda. Por isso, o comportamento dos sucessivos ocupantes terá um impacto fundamental no estado do refúgio. Efeitos cumulativos podem dar-se. Tal é o caso quando o lixo se acumula ou quando utensílios são deixados por montanhistas que não necessitam mais deles. Os efeitos decorrentes do exemplo desempenham um papel neste contexto. Isto implica que a existência de gerações negligentes tenderá a desencorajar as gerações posteriores a agir positivamente. Pode-se naturalmente tentar assegurar desde o início que o refúgio seja arquitecturalmente tão robusto quanto possível, resistindo em caso de degradação voluntária por parte de alguns dos sucessivos grupos - da mesma maneira que as casas de banho públicas com lavagem automática. Independentemente da robustez do refúgio, encontramos sempre, sobre uma mesa ou uma prateleira, um livro de registo sobre o qual está impressa a lista de regras a ser seguidas por cada montanhista. Seguem-se quatro exemplos, recolhidos virtualmente, em vigor neste tipo de refúgio de montanha:

\begin{tabular}{|l|l|}
\hline Regra 1 & $\begin{array}{l}\text { "Deixe o refúgio (...) tão limpo quanto gostaria de o encontrar - limpe } \\
\text { o lixo de outros ocupantes se necessário"7 }\end{array}$ \\
\hline Regra 2 & "Por favor deixe[-o] nas mesmas boas condições em que o encontrou"8 \\
\hline
\end{tabular}

\footnotetext{
${ }^{6}$ Devo este ponto a A. Cappelen e D. Heyd.

7 Traduzido do inglês. No original, "Leave the hut (...) as tidy as you would like to have found it - clean up other people's litter if necessary". http://www.sbwc.org.au/ TipsandRecipes.htm. Ver também: “... porque deve fazer ao seu filho aquilo que gostaria que o seu pai lhe tivesse feito" (traduzido do inglês) (Mauss, 1968: 140).

${ }^{8}$ Traduzido do inglês. No original, "Please leave [it] in the same good condition that you found it". http://fallcreekcottage.tripod.com/. Ver também: "Cada utente deixará a casa de banho pelo menos tão asseada e higiénica como antes da sua utilização" ("Each person shall leave the restroom in at least as neat and sanitary a condition as before such person's use of the restroom", versão original; Hayward Area Recreation and park District, Canadá, Regulations Governing Use of Parks, Recreation Areas, and Facilities, section 12, http://www.haywardrec.org/ admindocs/RegulationsHandbook.pdf); "Por favor deixe a sala de reuniões no seu estado inicial" ("Please leave the meeting room in its initial state", traduzido para inglês pelo autor; Ministério Federal belga para os Assuntos Sociais; porta de sala de reuniões, Agosto de 2004).
} 


\begin{tabular}{|l|l|}
\hline Regra 3 & $\begin{array}{l}\text { "Por favor deixe o refúgio num estado melhor do que aquele em que o } \\
\text { encontrou"9 }\end{array}$ \\
\hline Regra 4 & "Os montanhistas (...) devem deixar o refúgio limpo e arrumado"10 \\
\hline
\end{tabular}

Tabela 1: quatro regras de refúgios de montanha

Estilisticamente estes exemplos reais não são bem conseguidos. As últimas palavras da regra 1 deveriam ser abandonadas, tal como a palavra "boas" na regra 2. O que é interessante é que cada uma destas regras, uma vez purificadas e generalizadas, correspondem na verdade a diferentes princípios de justiça intergeracional. Daqui em diante, vamos destacar algumas das diferenças significativas entre estas quatro regras, bem como alguns dos desafios com que elas se deparam. Iremos também chamar a atenção na próxima seç̧ão para a ausência de um guardião, bem como, na terceira secção, para dois elementos ausentes da metáfora.

\subsection{Cleronomicidade, suficientarianismo e regras de ouro}

Consideremos uma primeira perspectiva destas regras. As regras 1 e 4 não fazem referência ao comportamento das gerações precedentes, ao que nos foi legado. Em contraste, as regras 2 e 3 claramente tomam o comportamento das gerações anteriores como ponto de referência. Estas podem pois ser adjectivadas como regras cleronómicas, na medida em que definem o que devemos à próxima geração tendo como base o que efectivamente herdámos das precedentes. A vantagem é que tal fornece-nos um ponto de referência relativamente claro num domínio no qual de outra forma podemos ter dificuldade em identificar o que é requerido pela justiça. Note-se, não obstante, que este ponto de referência pode flutuar conforme a ideia que a geração anterior tinha acerca das suas próprias obrigações e conforme o grau de observância dessas obrigações. A maioria das teorias de justiça revela-se na verdade como cleronómica, uma vez aplicadas ao domínio intergeracional. Esse é certamente o caso do igualitarismo, do utilitarismo, do libertarianismo de esquerda e da reciprocidade indirecta, pelo menos no que respeita às regras de ouro que traduzem os seus requisi-

\footnotetext{
${ }^{9}$ Traduzido do inglês. No original, "Please leave the hut in a better condition than you found it". http://alpineclubofcanada.ca/facility/rules.html. Ver também "ele tem a solene responsabilidade de proteger e melhorar o ambiente para as gerações presentes e futuras" (versão original, "he bears a solemn responsibility to protect and improve the environment for present and future generations") (itálicos do autor) PNUMA, princípio 1, Declaração de Estocolmo de 1972 da Conferência das Nações Unidas sobre o Ambiente Humano.

10 Traduzido do inglês. No original, "Hikers (...) are expected to leave the hut in a clean and tidy condition". http://www.kznwildlife.com/cobham_trails.htm.
} 
tos fundamentais. ${ }^{11}$ Em contraste, as regras 1 e 4 ilustram dois tipos de não-cleronomicidade.

No caso da regra 4, um dado padrão é estabelecido ("limpo e arrumado"). Ele deve ser respeitado por cada geração, independentemente do que tiver sido herdado da geração precedente. Se um grupo de montanhistas chegar ao refúgio e este se encontrar sujo e desarrumado como resultado da negligência acumulada dos montanhistas precedentes, o grupo de montanhistas recém-chegado deve resolver o problema. Na verdade existe uma teoria de justiça que é, neste primeiro sentido, não-cleronómica: o suficientarianismo. ${ }^{12}$ Ela requer simplesmente que cada geração deixe à próxima $o$ suficiente para cobrir as suas necessidades básicas. A famosa definição de sustentabilidade do Relatório Bruntland requer precisamente um desenvolvimento que "Responde às necessidades do presente sem comprometer a capacidade das gerações futuras de responder às suas próprias necessidades" (WCED, 1987:53). ${ }^{13}$

Para além da possibilidade de regras substantivas que não sejam cleronómicas, há também a de meta-regras não-cleronómicas. A regra 1 demonstra esta segunda estratégia não-cleronómica. Ela constitui uma meta-regra do tipo "regra de ouro". ${ }^{14}$ Não nos diz directamente $o$ que devemos aos outros - seja como montanhistas ou como gerações. Ao invés, diz-nos como devemos descobrir o que lhes devemos. O procedimento proposto não se refere às acções ou preferências dos nossos predecessores. Não toma como único ponto de referência o estado do mundo que herdámos, como resultado das preferências, acções ou omissões daqueles que ocuparam o planeta antes de nós. Naturalmente, a regra 1 não pode ignorar completamente, uma vez traduzida numa regra substantiva, o que uma dada geração efectivamente herdou - a menos que admitamos que ela irá necessariamente impor a adopção de um princípio suficientarista. Ainda assim, permanece em todo o caso como uma meta-regra não-cleronómica.

Consideremos agora as quatro seguintes meta-regras:

\begin{tabular}{|l|l|l|}
\hline $\begin{array}{l}\text { G deveria tratar G+1 } \\
\text { como... }\end{array}$ & Preferências & Deveres \\
\hline Regra 1 & $\ldots$ G quereria... & $\ldots$ que G-1 tivesse tratado G \\
\hline Regra 1' & $\ldots$ G quereria... & $\begin{array}{l}\ldots \text { receber }(\text { de } \text { G) caso fosse } \\
\text { G+1 }\end{array}$ \\
\hline
\end{tabular}

\footnotetext{
11 Gosseries (2008a).

12 Sobre o suficientarianismo: Casal (2007).

${ }^{13}$ Nota do tradutor: no original, "Meets the needs of the present without compromising the ability of future generations to meet their own needs".

${ }^{14}$ Ver também Wade-Benzoni (2002: esp. 1014).
} 


\begin{tabular}{|l|l|l|}
\hline Regra 1” & $\ldots \mathrm{G}+1$ quereria... & ...que G tivesse tratado $\mathrm{G}+1$ \\
\hline Regra 2 & $\ldots \mathrm{G}+1$ quereria... & ... que G-1 tivesse tratado $\mathrm{G}$ \\
\hline
\end{tabular}

Tabela 2: Meta-regras intergeracionais $(\mathrm{G}=$ geração presente, $\mathrm{G}+1=$ geração futura, $\mathrm{G}-1=$ geração anterior)

A tabela 2 permite-nos ver mais perto as primeiras duas linhas da tabela 1 , com uma meta-reformulação da regra 2 e duas alternativas à regra 1. Para poder comparar estas meta-regras e compreender o que elas significam, consideremos primeiro possíveis requisitos para regras de ouro intergeracionais. Poder-se-á dar alguma importância ao facto de, em cada meta-regra, o detentor da preferência dever divergir tanto do real detentor do direito quanto do real beneficiário. Isto reduziria os riscos de deveres ou demasiado brandos, ou demasiado exigentes. Aqui contudo, iremos propor um requisito mais simples que previna estes dois riscos: o real detentor do direito deve ser também o hipotético beneficiário (chamemos-lhe o requisito "dois chapéus"). O que está em jogo nestas meta-regras não é meramente a ideia de uma efectiva troca de papéis. O que é crucial para a sua força heurística é o facto de tal troca ser hipotética, não real. Isto força os indivíduos a tanto a (de um ponto de vista hipotético) se colocarem no lugar das outras pessoas como a (realmente) permanecer no seu próprio lugar. Quando se trata de analisar as relações entre potenciais detentores de deveres e potenciais detentores de direitos, isto é fundamental. A troca de papéis hipotética força-nos a imaginar-nos a nós mesmos como reais detentores de deveres sendo simultaneamente (e hipoteticamente) os beneficiários de tais deveres. Cognitiva e motivacionalmente, isto é interessante. Força-nos a exercer tanto a nossa imaginação (para antecipar devidamente as consequências das nossas acções) como a nossa imparcialidade (dado que exercemos dois papéis ao mesmo tempo). O mecanismo chave é o facto de ter de suportar os encargos e obter os benefícios.

Testemos agora o requisito "dois chapéus" de cada uma das regras listadas na tabela 2. A regra 1 é invocada, por exemplo, por Rawls. ${ }^{15}$ Segundo esta regra, $\mathrm{G}$ é o real detentor do dever, o real detentor da preferência e o hipotético beneficiário, G-1 é o detentor hipotético do dever e G+1 é o real beneficiário. G claramente usa os "dois chapéus". A regra 1' é usada por,

15 Rawls (2001: 160): “os membros de qualquer geração (e por isso todas as gerações) adoptariam como princípio o que elas quereriam que as gerações precedentes tivessem seguido, não importa quão temporalmente longínquo" (versão original: "members of any generation (and so all generations) would adopt as the principle they would want preceding generations to have followed, no matter how far back in time"). 
por exemplo, Epstein. ${ }^{16}$ Segundo esta regra, G substitui G-1 como hipotético detentor de dever e $\mathrm{G}$ coloca-se no lugar de $\mathrm{G}+1$ como hipotético beneficiário. Assim, enquanto $\mathrm{G}+1$ é o verdadeiro beneficiário, $\mathrm{G}$ é o verdadeiro e o hipotético detentor do dever, o hipotético beneficiário bem como o detentor da preferência. O requisito dos dois chapéus é por conseguinte também respeitado, ainda que a regra 1' se baseie em apenas duas posições $(\mathrm{G}$ e $\mathrm{G}+1)$ em oposição a três $(\mathrm{G}-1, \mathrm{G}$ e $\mathrm{G}+1)$.

Na regra 1", tal como na regra 1', há apenas duas posições $(\mathrm{G}$ e $\mathrm{G}+1)$. $\mathrm{G}+1$ é o real detentor da preferência e o real e hipotético beneficiário, enquanto $\mathrm{G}$ é simultaneamente o real e o hipotético detentor do dever. O "requisito dos dois chapéus" não é por isso respeitado. Na regra 2, o detentor da preferência é G-1, o detentor do dever é $\mathrm{G}$ e o beneficiário é $\mathrm{G}+1$. Ao invés de um real e um hipotético detentor de deveres, há na verdade dois reais detentores de deveres: G-1, que já transferiu algo a G; e G, que irá com base nisso transferir algo a $\mathrm{G}+1$. Similarmente, há dois reais beneficiários. $\mathrm{G}$ e $\mathrm{G}+1$. É por isso que a regra 2 não é uma regra de ouro, dado que não depende de uma troca de papéis hipotética. ${ }^{17}$ É verdade que $\mathrm{G}$ tem dois reais "chapéus" sob a regra 2. Contudo, dado que os benefícios já foram recebidos, não afectam motivacionalmente a sua posição na medida em que os deveres não são tão fortes quanto no caso hipotético e no dos dois chapéus "simultâneos".

As regras 1 e 1' respeitam ambas o requisito dos "dois chapéus" ao passo que a regra 1" claramente não. Note-se para além disso que deixámos de parte nesta discussão a questão das preferências de referência. Presumimos aqui que o requisito dos hipotéticos dois chapéus é o ingrediente chave. Existe uma questão suplementar: decidir a quem pertencem as preferências de referência. Este é um problema que todas as regras de ouro têm de responder, independentemente de lidarmos com questões intergeracionais ou não. ${ }^{18} \mathrm{E}$ este é um problema de raiz dado que, prima facie, não há qualquer razão óbvia para que as minhas preferências sejam mais aceitáveis que as do meu vizinho na decisão de como tratá-lo. Será óbvio se eu for um masoquista e ele for alguém demasiado exigente que não se importe que os outros exijam muito dele também. Podemos contudo pelo menos esperar que o requisito dos dois chapéus hipotéticos provavelmente filtre até certo ponto as preferências problemáticas. Por sua vez isto expli-

16 Epstein (1992: 84) "o que quereríamos que a presente geração fizesse caso estivéssemos no lugar de uma futura geração por nascer?" (versão original, "what would we want the present generation to do if we were in the shoes of some future unborn generation?").

${ }^{17}$ Compare-se com Masson (1999: 83, nota 14) (distinção passado real/ passado fictício).

${ }^{18}$ Hooker (2005). Ver também Parfitt (2010: capítulo 14). 
ca-nos por que motivo a regra 1" é também problemática: não é o detentor da preferência quem hipoteticamente usa os dois chapéus, o que não permite que este mecanismo de filtragem se dê. ${ }^{19}$

\subsection{Inobservância, despoupança ${ }^{20}$ e acumulação}

Outra característica interessante das regras 1 a 4 tem que ver com as suas características em caso de inobservância por uma das gerações. A inobservância é um problema sério para a justiça intergeracional. Isto deve-se não apenas devido ao grande número de gerações, mas também, como adiante discutiremos, por causa dos desafios que tal contexto coloca à possibilidade de coacção. A inobservância deve portanto ser especialmente tomada a sério num tal contexto. A cleronomicidade é aqui relevante, sendo notável o contraste entre as regras 2 e 4 . Sob a regra 2, se G-1 não cumprir com as suas obrigações o grau de exigência das obrigações de $\mathrm{G}$, bem como de todas as gerações seguintes, diminuirá também. Tal não significa que a despoupança - isto é, transferir menos às gerações seguintes do que aquilo que herdámos da anterior - seja moralmente aceite. Contudo, o que será transferido irá diminuir gradualmente devido à inobservância de algumas das sucessivas gerações. Uma regra cleronómica que tome como ponto de referência sequencialmente o que foi herdado da geração anterior é incapaz de evitar que tal diminuição se dê. Para haver um melhoramento gradual que preencha as brechas causadas pela inobservância de algumas das gerações será então necessário depender da boa vontade das sucessivas gerações.

Em contraste, a regra 4, por não ser cleronómica, tem propriedades muito diferentes. Num contexto de total observância, a regra 4 poderia ser menos exigente que a regra 2 se "limpo e arrumado" for definido em termos minimalistas. O suficientarianismo como versão da regra 4 apresenta-nos um caso peculiar, pois é compatível com a despoupança caso tenhamos herdado mais que o necessário para cobrir as necessidades básicas individuais. Em contraste, num contexto mais realista de inobservância de algumas das gerações, a regra 4 oferece mais garantias contra uma diminuição total. Isto torna-a mais resistente, na medida em que a sua insensibilidade face à inobservância garante um mínimo. Isto é algo que a

${ }^{19}$ Note-se contudo que devido a preferências adaptativas, é mais provável que $\mathrm{G}+1$ esteja contente com o mundo tal como o herdou, que $\mathrm{G}$ com as mudanças que o mundo sofreu (por exemplo devido aos efeitos da idade), reduzindo possivelmente os pedidos de $\mathrm{G}+1$ face a F. Devo a B. Hooker esta nota.

${ }^{20}$ Nota do tradutor: conceito económico, significando a transformação da poupança em consumo. 
regra 2 é incapaz de garantir em caso de inobservância significativa mesmo por parte de poucas gerações. Não obstante, tal robustez da regra 4 tem um preço associado. O preço de fazer recair sobre cada uma das sucessivas gerações o peso de compensar desequilíbrios, em vez de esse peso estar distribuído pelas sucessivas gerações. Se eu herdar um mundo muito sujo e desordenado, eu serei forçado a garantir que os seguintes utilizadores herdem de mim um mundo limpo e arrumado de novo.

Assim, a cleronomicidade não tem apenas que ver com o fornecimento de um dado ponto de referência. Ela também responde de certa forma à questão da inobservância pelas gerações precedentes. Curiosamente, se cada geração violar as suas obrigações intergeracionais, a natureza das nossas obrigações será também modificado no caso de uma regra cleronómica. Em contraste, as obrigações impostas a cada geração pela regra 4 não são nem afectadas pela ideia que as anteriores gerações tinham a respeito das suas próprias obrigações, nem pelo grau de real observância das gerações face à sua ideia de obrigação. Ou seja, segundo a regra 2 , em caso de inobservância, todas as seguintes gerações terão de lidar com as consequências de tal inobservância, ao passo que nenhuma delas será especialmente responsável pela sua resolução. As consequências para os que respeitem a regra serão especialmente relevantes pois cada caso de inobservância irá reduzir ainda mais o montante que é suposto cada geração transferir à seguinte. Em contraste, a regra 4 toma este risco de inobservância a sério. Contudo, acarreta duas desvantagens. Em primeiro lugar, a despoupança é permitida até certo ponto, nomeadamente desde que permaneçamos acima do limiar da limpeza e arrumação (na metáfora) ou da suficiência (no equivalente do mundo real). Em segundo lugar, o peso da fixação das consequências da inobservância recairá por inteiro sobre cada uma das gerações seguintes. Um dos desafios consiste pois em encontrar uma teoria que possa manter a resiliência da regra 4 sem impor o peso da re-acumulação sobre uma só geração.

Consideremos agora as nossas quatro regras de um outro ângulo. A regra 3 requer que a acumulação se dê sempre. Isto é menos frequentemente defendido. Isto requer que cada geração participe no processo de acumulação. O utilitarismo é a perspectiva que tende a mais frequentemente requerer tal acumulação. Ela visa a maximização do bem-estar intergeracional. Dado que o investimento pode ser produtivo - com a passagem do tempo e mesmo na ausência de melhoramentos tecnológicos - os utilitaristas pedem às gerações anteriores que renunciem a algum consumo presente porque a riqueza que não seja consumida hoje, mas antes investida, pode corresponder a mais consumo no futuro. Nem a regra 2 nem a 4 pedem tal acumulação, excepto no caso de inobservância no âmbito da regra 4.

Esta ideia de acumulação requereria extensa discussão. Vou aqui apenas mencionar dois pontos. Primeiro, os utilitaristas não são os únicos a 
defender uma obrigação de transferir mais para a próxima geração do que o que herdámos da anterior. Rawls, por exemplo, defende-o até certo ponto ao defender uma fase de acumulação. Contudo ele fá-lo por razões diferentes das dos utilitaristas. ${ }^{21}$ Segundo, a ideia de acumulação constitui um enorme desafio para igualitaristas (de tipo leximin). ${ }^{22}$ Ela requer que os menos abastados (as gerações anteriores) apertem os cintos em benefício das gerações posteriores, mais ricas, beneficiando estas de um tal processo de acumulação. Num tal mundo de acumulação os menos abastados não estão numa situação tão boa quanto em mundos intergeracionais alternativos seguindo caminhos diferentes. Dito de outra maneira, a ideia de crescimento em favor dos mais pobres é mais difícil de defender num esquema intergeracional em que os mais pobres devem ser os investidores do que num esquema intrageracional. Parece pois inevitável que a própria ideia de acumulação irá violar o objectivo de optar por um percurso intergeracional de tipo leximin tal que os menos afortunados, qualquer que seja a sua geração, fiquem numa posição tão boa quanto possível. Em princípio, uma vez alcançado um determinado limiar de riqueza, os igualitaristas de tipo leximin deveriam tanto advogar que não existisse uma obrigação geracional de poupar, como também uma proibição de poupanças geracionais. Deveriam fazê-lo porque se temos um excedente relativamente ao que herdámos, deveremos dá-lo aos membros menos favorecidos dentro da nossa própria geração. Tal deve ser o procedimento, não por parcialidade geracional, mas simplesmente porque tal regra, se seguida por cada uma das gerações, seria a mais favorável aos menos afortunados independentemente da sua geração. Por conseguinte, seria injusto, não apenas a obrigação de contribuir para o processo de acumulação como o simples facto de autorizar uma tal acumulação. ${ }^{23}$

${ }^{21}$ Gaspart \& Gosseries (2007).

$22 \mathrm{O}$ conceito de igualitarismo leximin (ou maximin) refere-se a uma visão igualitarista que não se preocupa com desigualdades de x enquanto tal. Em vez disso, preocupa-se se um dado sistema ou prática irá contribuir para um mundo em que o menos abastado de um tal sistema ou prática está numa melhor situação que os menos abastados de sistemas ou práticas alternativas. Em muitos casos, reduzir as desigualdades também irá melhor a situação dos menos abastados. Noutros casos, contudo, aumentar as desigualdades pode ser necessário para melhorar a situação dos menos abastados, normalmente devido à questão dos incentivos. Neste último tipo de situações o igualitarismo clássico de x não concordará com o igualitarismo leximin/maximin de $\mathrm{x}$. Outra coisa que é necessário compreender é que o leximin é uma forma lexicográfica de maximin que não se preocupa apenas com o menos abastado, mas também com o segundo menos abastado, etc., de uma forma lexicográfica. Ver por exemplo Van Parijs (1991:173, nota1).

${ }^{23}$ Uma versão menos concisa deste argumento pode ser encontrada em Gaspart \& Gosseries (2007). 


\section{A ausência de um guarda de refúgio}

As quatro regras constituem um rico panorama de questões em aberto e inesperadas dificuldades. Existe contudo outro aspecto característico da metáfora que deve atrair a nossa atenção: o refúgio não tem um guarda. Assim, o seu estado depende inteiramente dos eventos naturais e do comportamento de cada um dos sucessivos grupos de montanhistas. Não existe um guarda que garanta que os sucessivos montanhistas cumprirão efectivamente as regras do refúgio, que limpem a sujidade quando não foram eles os causadores e muito menos que tomem a seu cargo pesados trabalhos de construção caso eventos naturais danifiquem o refúgio. No caso de contemporâneos, conhecemos os esforços dos teóricos do contratualismo para estabelecer a necessidade e legitimidade de um poder susceptível de impor a todos o respeito de algumas regras. No plano intergeracional tal é muito mais difícil de defender. Dependemos pois dos nossos pares, sem um terceiro elemento que garanta a observância das regras, tome conta ou, se necessário, restabeleça a ordem.

Para ser mais precisos, a observância das regras não será apenas provavelmente mais difícil de garantir. Ela é também muito mais necessária por causa da dependência de cada geração sobre as outras. Transferências directas para lá das gerações imediatamente contíguas são impossíveis - excepto bombas-relógio. Para ser mais precisos, o problema da dependência toma duas formas. Em primeiro lugar há a dependência ascendente: $\mathrm{G}+1$ depende inteiramente do que $\mathrm{G}$ lhe deixou - esquecendo a difícil questão das invenções de $\mathrm{G}+1$ e das transferências exógenas. Em segundo lugar, existe uma dependência descendente: esquecendo as bombas-relógio, se $\mathrm{G}$ quiser garantir que $\mathrm{G}+3$ herde determinado tipo de bem, irá depender quase inteiramente de $\mathrm{G}+1$ e $\mathrm{G}+2$. Se falarmos de $\mathrm{G}+100$ ou $\mathrm{G}+1000$ existe como é óbvio uma questão ainda mais significativa. Cada geração depende pois, para o que tem, das anteriores; e das seguintes intermediárias para as transferências a futuras gerações mais remotas. A inobservância por parte de uma só geração pode de facto ter repercussões sobre todas as sucessivas gerações, sobretudo se o caminho segue regras cleronómicas, o que não acontece geralmente num esquema intrageracional. A observância das regras é pois um sério problema em contexto intergeracional.

\subsection{Garantir benefícios mútuos}

O problema da inobservância é especialmente importante para teorias de justiça contratualistas neo-hobbesianas. ${ }^{24}$ Para estas, a própria existência

${ }^{24}$ Gauthier (1986: IX-6.1). 
de obrigações intergeracionais requer o respeito de duas condições. Primeiro, a cooperação tem de ser capaz de gerar um excedente que seja benéfica para ambos os jogadores envolvidos. Segundo, é preciso poder garantir que ambos os jogadores cumprirão as suas obrigações mutuamente benéficas. Tudo se torna mais complexo se tomarmos a sério o facto de que, além das três ou quatro gerações contemporâneas em cada momento na História, muitas mais gerações não estarão em contacto umas com as outras. Consideremos esta questão mais perto.

A ideia de vantagens mútuas pressupõe primeiro que o excedente resultante da cooperação seja benéfico para ambas as partes, e neste caso para ambas as gerações cooperantes. Limitemo-nos a duas gerações. A possibilidade de beneficios descendentes, isto é, benefícios acrescidos para a segunda geração não levanta quaisquer dificuldades no caso de sobreposição geracional. Em contraste, na ausência de uma tal sobreposição, e se considerarmos a transmissão da linguagem como crucial (por exemplo para transferir cultura, tecnologia, etc.), isto iria reduzir dramaticamente, para a segunda geração, o valor da maior parte dos objectos materiais (por exemplo um computador sem qualquer guia de utilizador compreensível). Quanto aos beneficios ascendentes, isto é, aqueles indo da segunda para a primeira geração, Rawls insiste no facto de que "os reais benefícios económicos fluem apenas numa direcção". ${ }^{25}$ Isto não é necessariamente verdadeiro, o que é demonstrado pela possibilidade de reembolso da dívida externa contraída pelos nossos pais ou de tomar conta deles quando se tornem idosos. Se o caso do cuidado dos idosos pressupõe uma sobreposição, tal não é absolutamente certo no caso da dívida externa. Contudo, neste caso pressupõe-se notoriamente uma economia aberta.

Permanece pois a possibilidade de benefícios mútuos, pelo menos no caso de sobreposição geracional. E quanto à possibilidade de mútua coacção, garantindo que tais benefícios mútuos se irão efectivamente verificar? Para prevenir a ocorrência de inobservância será cada geração capaz de ameaçar de forma credível as gerações contíguas com as quais é suposto colaborar? Ameaças descendentes, ou seja, aquelas feitas pela primeira à segunda geração caso esta não respeite os deveres ascendentes, podem ser previstas no caso de sobreposição intergeracional. No entanto, e quanto às ameaças ascendentes, ou seja, aquelas feitas pela segunda à primeira geração? É aqui que as mais sérias dificuldades aparecem. A sobreposição é absolutamente necessária neste caso, em particular porque a sanção só pode ser imposta após a violação da regra intergeracional se ter dado. Como poderia uma geração posterior impor uma sanção a outra mais antiga após a violação de uma regra, se essa mesma geração já não existe? Mais ainda,

25 Rawls (1999: 254). No original, "actual economic benefits flow only in one direction". 
se aceitarmos a ideia de que o que herdamos é inteiramente canalizado pela geração precedente, sancioná-la expõe-nos ao perigo de receber menos, pelo menos enquanto tal sanção tomar forma patrimonial, directa ou indirectamente. Excepto o caso de sanções simbólicas, qualquer sanção ascendente equivaleria de facto a dar um tiro no pé, ou seja, a uma auto-sanção. ${ }^{26}$

\subsection{Rigidez, altruísmo e educação}

A ausência de um guarda capaz de garantir que as regras do refúgio sejam efectivamente respeitadas levanta uma dificuldade crucial, tal como acabámos de apontar. Isto pode contudo ser matizado através da referência a duas dimensões, a primeira das quais está claramente presente tanto na metáfora quanto no mundo real e a segunda mais no mundo real que na metáfora. A primeira dimensão pode ser designada como resiliência, robustez ou rigidez. Insistimos acima no facto de que um refúgio de montanha pode ser construído de forma tal que pode resistir especialmente bem a um mau tratamento por algumas das sucessivas gerações. Isto tornaria a regra mais difícil de ser violada, ou as consequências de tal violação por apenas uma geração menos visíveis. Há equivalentes disto no mundo real e não apenas ao nível arquitectónico. Os limites de revisão constitucional são um bom exemplo. Tornar as constituições mais difíceis de mudar do que as leis vulgares é claramente uma infracção à soberania geracional das gerações futuras. Contudo, isto também reduz o risco de futuras gerações desleixadas modificarem pontos essenciais das constituições sem o devido cuidado. Outro bom exemplo é o do armazenamento a longo-prazo de resíduos radioactivos. Soluções que deixem opções abertas às futuras gerações também aumentam os riscos em outros aspectos, tornando todas as gerações potencialmente mais vulneráveis ao comportamento de futuras gerações descuidadas. Consideremos um relatório da OCDE NEA no campo da gestão de resíduos radioactivos:

"as nossas responsabilidades face às futuras gerações são melhor respondidas através de uma estratégia de armazenamento final do que numa dependência de armazenamento que requeira vigilância, legando responsabilidades de guarda de longo-termo e que podem em dado momento ser negligenciadas por futuras sociedades cuja estabilidade estrutural não pode ser presumida". ${ }^{27}$

\footnotetext{
26 Ver Gosseries (2008: secção IV).

${ }^{27}$ No original, "our responsibilities to future generations are better discharged by a strategy of final disposal than by reliance on stores which require surveillance, bequeath long-term responsibilities of care, and may in due course be neglected by
} 
A ideia é claramente que as escolhas relativamente ao armazenamento dos resíduos radioactivos - tipicamente referidos como questões de reversibilidade e reparabilidade - devem tomar a sério o problema da dependência descendente, ou seja, até que ponto o bem-estar de gerações de um futuro remoto dependerá do que as gerações futuras intermediárias farão ou não.

Para além da questão da rigidez e da robustez, queremos fazer notar outra dupla dimensão que está mais presente no real contexto intergeracional que na metáfora do refúgio de montanha. Estas dimensões são directamente relevantes para a questão da credibilidade das ameaças ascendentes ou descendentes. Por um lado, cada geração é gerada pela anterior, ao contrário do que acontece no caso dos montanhistas, os quais não experienciam tal tipo de relação. Enquanto os grupos de montanhistas se seguem uns aos outros, as gerações têm relações genéticas e parentais entre si, pelo menos numa sociedade em que o grupo daqueles que são - ou em tempos foram - pais permaneça suficientemente maior que o grupo daqueles que não são - ou nunca foram - pais. Regressaremos mais tarde a este ponto. Contudo, e no que concerne ao problema da observância, segue-se que no mundo real um forte altruísmo descendente reduz até certo ponto a necessidade (pelo menos na sobreposição) de ameaças ascendentes credíveis. Por outro lado, cada geração educa a próxima, inclusive através de um conjunto de valores. Isto reduz a necessidade de ameaças descendentes. Estes dois fenómenos - altruísmo descendente e educação - reduzem a intensidade do problema. Ele não desaparece, contudo.

\section{Duas dimensões ausentes}

\subsection{Génese, responsabilidade causal e não-identidade}

Permitam-me concluir com duas dimensões que são cruciais para qualquer teoria de justiça intergeracional e que estão ausentes da metáfora. A primeira é a génese. Num mundo de montanhistas cada um dos sucessivos grupos não é responsável pela própria existência dos seus sucessores, enquanto tal é o caso de um mundo intergeracional, como no-lo comprova o significado etimológico de "geração". A natureza genética das relações intergeracionais - ausente da metáfora - reforçará ou enfraquecerá as nossas obrigações intergeracionais? Vimos que ela enfraquece de forma indirecta a necessidade de ameaças porque a dimensão de educação que acompanha uma tal génese é devido ao altruísmo descendente. Há pelo menos uma razão para crer que a intensidade das nossas obrigações intergeracio-

future societies whose structural stability should not be presumed". Agência para a Energia Nuclear (OECD) (1995:5). Ver também Gosseries (2008c). 
nais poderia ser reforçada por este aspecto "genético". Enquanto pais nós somos causalmente responsáveis pela própria existência da geração seguinte. Isto é o que poderá explicar por exemplo uma assimetria entre obrigações filiais e parentais, por exemplo, no caso da justiça entre grupos etários. Como Daniels escreve, "Os deveres que estão associados à posição parental são aqueles que os pais tomam a seu cargo. Eles dão existência aos seus filhos - ou adoptam-nos - e é um tal acto que impõe deveres sobre o pai. (...) O papel de ser filho não é algo que assumamos da mesma maneira que assumimos a parentalidade". ${ }^{28}$ Isto levanta a seguinte questão: habitualmente vemos as obrigações intergeracionais como obrigações entre (grupos de) indivíduos sem qualquer ligação genética (excepto no problema adiante referido da não-identidade). Contudo, o facto de sermos a causa da existência da próxima geração, o que significa que a sua existência resulta fortemente da nossa escolha, não da sua, pode ter algum impacto na natureza e/ou intensidade das nossas obrigações para com ela. Esta é pelo menos uma significativa diferença entre justiça global e intergeracional, dado que na primeira não somos causalmente responsáveis pela existência daqueles que vivem na outra ponta do planeta, ou pelo menos não directamente.

Exactamente que diferença faria para nós olhar as obrigações intergeracionais como parcialmente "causais" ao invés de "meramente" comutativas ou distributivas? Limitemo-nos aqui ao fosso entre obrigações causais e distributivas. Consideremos três agentes, A, B e C. Imaginemos que C é o menos afortunado devido a circunstâncias naturais como um terramoto ou uma doença congénita. Para uma perspectiva distributiva leximin, A e B terão ambos uma obrigação para com $\mathrm{C}$. Consideremos agora um cenário alternativo em que a desvantagem experienciada por $\mathrm{C}$ é exactamente a mesma que no primeiro cenário. Contudo, neste caso a desvantagem resulta de uma acção danosa de A, ao invés de um fenómeno natural. Duas coisas podem daí resultar. Primeiro, para teorias dando uma significativa importância ao fosso entre acção e abstenção e tratando os recursos internos e externos de forma diferente, ao segundo cenário podem corresponder obrigações acrescidas para com $\mathrm{C}$, independentemente de sobre quem elas pesem. Podemos supor que, por exemplo, perspectivas libertárias tenderão a associar obrigações mais fortes a desvantagens causadas por outros indivíduos que aqueles resultantes da mera má sorte. Segundo, poder-se-á também dar o caso de, ainda que não fazendo qualquer diferença no que concerne à intensidade das nossas obrigações para com $\mathrm{C}$, a referência à responsabilidade causal iria incidir sobre a alocação de responsabilidades

${ }^{28}$ No original, "The duties that come with the role of parenting are ones that parents undertake. They bring their children into existence - or they adopt them - and it is this act that imposes duties on the parent. (...) The role of being a child is not one we undertake in the way we undertake the role of parenting”. Daniels (1988: 29). 
entre os potenciais detentores de deveres - aqui, entre A e B. No caso de uma visão distributivista, A e B teriam obrigações distributivas em conjunto em relação a C. No caso da responsabilidade causal, apenas A teria de compensar a desvantagem a que $\mathrm{C}$ está submetido.

O que pode isto implicar para o domínio intergeracional? Ver as obrigações intergeracionais sendo orientadas pela responsabilidade causal pode modificar a intensidade de tais obrigações, embora esse não seja provavelmente o caso, pelo menos no que concerne a teorias de justiça distributivas. Tal pode também influenciar a partilha intergeracional de responsabilidades. De facto, a forma peculiar como a regra 4 impõe a responsabilidade total em cada geração - como vimos anteriormente - pode na verdade ser apoiada por uma intuição relacionada com a responsabilidade causal. Dado que cada geração é totalmente responsável pela própria existência da geração que se segue, seria aceitável impor também a obrigação total de deixar tudo em ordem para essa geração. Trazer uma nova geração ao mundo é uma escolha, certamente não uma obrigação. Esta escolha apenas poderá ser moralmente aceitável se oferecermos as devidas condições às crianças que trazemos ao mundo. Note-se, em terceiro lugar, que enquanto a responsabilidade causal pode explicar obrigações descendentes, não seria contudo capaz de explicar de forma directa obrigações ascendentes. Consequentemente, se acreditarmos que a justiça intergeracional implica obrigações nos dois sentidos - descendente e ascendente - o modelo de responsabilidade causal permanecerá necessariamente incompleto. ${ }^{29}$

Como vimos, interpretar as nossas obrigações intergeracionais em termos de responsabilidade causal pode aumentar a intensidade das nossas obrigações intergeracionais - pelo menos no que concerne às obrigações descendentes e isto em contraste com algumas das teorias distributivas existentes. Contudo, a dimensão genética das relações intergeracionais, sendo um factor que potencialmente as reforça, pode também ser uma po-

${ }^{29}$ Ele poderá talvez ser combinado com outras perspectivas para - indirectamente obrigações ascendentes. Por exemplo, uma perspectiva de dupla reciprocidade justificará a existência de obrigações ascendentes como resposta a uma transferência descendente: $\mathrm{G}$ deve $\mathrm{x}$ a G-1 porque G-1 transferiu x a G. Este cálculo "reactivo" das nossas obrigações intergeracionais é incapaz contudo de justificar as obrigações descendentes que accionam o processo. Tais obrigações descendentes poderiam ser justificadas com base na responsabilidade causal. Em tal caso combinar-se-ia responsabilidade causal descendente e obrigações ascendentes baseadas na reciprocidade. Sobre a dupla reciprocidade: Gosseries (2009). Note-se que ao passo que a responsabilidade causal entra aqui através da dimensão genética, há um outro ângulo através do qual pretensões de responsabilidade causal são expressas no domínio intergeracional, ou seja, quando os membros da geração presente entendem que uma reparação por danos passados é devida como indemnização. Ver Gosseries (2004b). 
tencial ameaça à própria possibilidade de existência de obrigações descendentes. Refiro-me aqui ao bem conhecido e amplamente debatido problema da não-identidade ${ }^{30} \mathrm{Em}$ resumo, a ideia da "não-identidade" foca o facto de muitas das nossas acções com influência no modo como surgirão futuras pessoas afectar simultaneamente a própria identidade dessas mesmas pessoas, ou seja, quem irá existir no futuro. Sempre que seja este o caso - o que por si já constitui um tópico de discussão - há o perigo de não nos podermos basear num conceito comparativo e contrafactual de dano. Para tal conceito, a possibilidade de obter uma indemnização requer a possibilidade de ser capaz de comparar o estado efectivo da pessoa (como resultado da acção alegadamente danosa) com um estado contrafactual da pessoa, caso a acção não se tivesse dado. Sempre que a acção alegadamente danosa seja também uma condição necessária à própria existência da alegada vítima encontramo-nos fora do âmbito do típico conceito de dano - e dentro do âmbito do problema da não-identidade. Se acharmos que as obrigações apenas podem fazer sentido se a sua violação fosse neste sentido danosa, as obrigações descendentes tornar-se-iam irrelevantes sempre que nos encontrássemos num contexto de não-identidade. Obviamente, vários caminhos podem ser propostos para resolver isto. $\mathrm{O}$ meu objectivo aqui é apenas assinalar o problema e insistir no facto de a génese ser uma faca de dois gumes dado que ela potencialmente reforça $e$ enfraquece as nossas obrigações intergeracionais descendentes.

\subsection{Demo-sensibilidade ${ }^{31}$}

Outra dimensão ausente das quatro regras do refúgio - ou que pelo menos não é mencionada - é o problema das flutuações demográficas. As questões de sobrepovoamento (no que concerne a recursos ambientais) ou de subpovoamento (no que concerne à sustentabilidade dos nossos sistemas de pensões) têm uma clara dimensão intergeracional. No caso dos montanhistas a variação do número dos sucessivos utilizadores do refúgio não tem aparentemente um impacto no conteúdo das suas obrigações. A limpeza e arrumação em particular não são necessariamente aumentadas de forma significativa caso esperemos que o próximo grupo de montanhistas seja maior, em parte devido à dimensão de não-rivalidade. ${ }^{32} \mathrm{Em}$ contraste, quando bens rivais são legados, a dimensão do grupo que se segue é claramente relevante para a dimensão das nossas obrigações. Em que sentido?

\footnotetext{
30 Parfit (1984: 351f.), Gosseries (2004a: capítulo 1).

${ }^{31}$ Deixamos de parte o problema da chamada "conclusão repugnante". Ver Parfit (1984).

32 Ver por exemplo Anderson \& François (1997).
} 
Primeiro, algumas teorias são demo-sensitivas, ou seja, elas adaptam o conteúdo das nossas obrigações à respectiva dimensão das gerações em causa. Algumas teorias não são demo-sensíveis, como as perspectivas de reciprocidade indirecta. ${ }^{33} \mathrm{Em}$ contraste, as teorias utilitarista, igualitarista e suficientarianista são-no. Consideremos o caso de duas gerações sucessivas: $\mathrm{G}$ é composta por dez membros e $\mathrm{G}+1$ por cem. Se o que cada geração herdasse não fosse legado pela geração precedente, mas simplesmente caísse do céu, um igualitarista certamente defenderia que $\mathrm{G}+1$ deveria herdar dez vezes mais que G. Contudo, se sairmos da situação do "maná celeste", surgem duas dificuldades adicionais apontando em sentidos inversos. Por um lado, o que cada geração herda não vem (apenas) do céu. É herdado da geração anterior e resulta dos esforços activos e passivos desta última. Portanto, esperar que $\mathrm{G}+1$ herde dez vezes mais do que $\mathrm{G}$ herdou coloca um peso enorme sobre G. Se G não fosse responsável pela dimensão de $\mathrm{G}+1$, tal seria provavelmente considerado um peso excessivo. Os igualitaristas defenderiam provavelmente algo entre transferir o mesmo que $G$ herdou e transferir dez vezes mais do que $G$ herdou. A regra 3 pode também fazer sentido a partir de uma tal perspectiva, caso consigamos realisticamente presumir que a população irá aumentar a nível global. Contudo, por outro lado, $\mathrm{G}$ não é apenas a origem da herança de $\mathrm{G}+1$. É também responsável pela dimensão de $\mathrm{G}+1$. É pois a união da natureza endógena do que $\mathrm{G}+1$ herda e a natureza endógena da dimensão de $\mathrm{G}+$ lque pode tornar aceitável esperar que $G$ transfira dez vezes mais aquilo que herdou, caso $G$ decida aumentar a população em dez vezes. Notemos que a demo-sensibilidade funciona nos dois sentidos, o que também significa que em caso de redução populacional estaremos autorizados a transferir à próxima geração menos do que herdámos.

Segundo, outra dimensão importante está relacionada com a diferença entre o problema população-ambiente e o problema população-pensões. No primeiro caso estamos preocupados com a quantidade de pessoas que têm de viver com um dado conjunto de recursos. E é primariamente o rácio entre esse conjunto e o número dos seus utilizadores que nós pretendemos manter constante. No caso das pensões é a dimensão relativa das sucessivas gerações que nos preocupa. O que está em jogo não é um problema de rácio entre população e recursos, mas antes um rácio população-população. Portanto, fazendo a demo-sensibilidade sentido em ambos os casos, a equidade na transferência de recursos e na sustentabilidade financeira das pensões requer diferentes tipos de ferramentas.

${ }^{33}$ Ver Gosseries (2009: secção 4). 


\section{Conclusões}

Não devemos esperar que a metáfora do refúgio de montanha nos dê um procedimento orientador que nos ajude a encontrar a resposta certa a alguns destes desafios normativos, da mesma maneira como o esperamos - frequentemente de forma demasiado optimista - de mecanismos como a posição original de Rawls. A metáfora dá-nos antes um mundo, mais pobre mas real, com fortes paralelos com algumas dimensões normativas centrais do nosso mundo intergeracional, o qual pode ser usado para clarificar e testar as nossas intuições normativas sobre justiça intergeracional, tal como os casos de barcos salva-vidas ou dos carrinhos em outras esferas da filosofia moral e política. Contudo, não desenvolvemos aprofundadamente as nossas intuições normativas. O que fizemos em vez disso foi sublinhar a natureza de algumas destas especificidades intergeracionais (especialmente a cleronomicidade e a génese) e as suas potenciais implicações para as teorias de justiça.

Começando pela metáfora, enfatizámos as diferenças relevantes entre as quatro regras de refúgios. Algumas delas - as regras 1, 1' e 1" - são do tipo "regra de outro", enquanto outras - regras 2 a 4 - são substantivas, exibindo diferentes propriedades em termos de cleronomicidade e/ou de partilha de responsabilidades em caso de não-observância. A ausência de um guarda é igualmente uma característica com implicações significativas, dada a importância da questão da observância das normas.

Afirmámos que o valor heurístico da metáfora depende também das suas diferenças face ao cenário intergeracional. De entre tais diferenças, explorámos as implicações normativas da relação "genética" entre as gerações, a qual não existe entre sucessivos grupos de montanhistas. Tais implicações podem, como vimos, ter consequências em sentidos opostos. Finalmente, sublinhámos a importância das variações populacionais para uma teoria de justiça intergeracional.

\section{SUMÁRIO}

Neste artigo, exploramos até que ponto os refúgios de montanha e as regras impostas aos utilizadores deste tipo de alojamento colectivo temporário podem fornecer-nos uma inspiração metafórica na exploração das questões relativas à justiça intergeracional. Indicamos aqui características que a metáfora torna mais salientes. Focamos em particular as regras intergeracionais de ouro e a justiça cleronómica (seç̧ão 1). Explicamos também por que motivo é relevante a ausência de um guardião (secção 2). Outras características ausentes salientam outras dimensões que são centrais para a justiça intergeracional. Atenção especial é dada a duas delas: a relação de "génese" entre sucessivas gerações e o problema das alterações populacionais ao longo das gerações (secção 3). 
Palavras-chave: justiça intergeracional, reciprocidade, regra de ouro, justiça cleronómica, suficientariansmo, sobreposição de gerações, incumprimento, alteração populacional, sustentabilidade.

\begin{abstract}
In this paper, we explore the extent to which mountain huts and rules imposed on their users can provide metaphoric inspiration to the exploration of issues of an intergenerational justice. We indicate features made salient by the metaphor. We focus in particular on the content of an intergenerational golden rule and on cleronomic justice (Sect. 1). We also explain why the absence of a warden matters (Sect. 2). Other absent features make salient other dimensions that are central to intergenerational justice. Special attention is granted to two of them: the "genesis" relationship among successive generations and the problem of population change across generations (Sect. 3).
\end{abstract}

Keywords: intergenerational justice, reciprocity, golden rule, cleronomic justice, sufficientarianism, overlapping generations, non-compliance, population change, sustainability.

\title{
Bibliografia
}

Anderson, S. \& P. François, 1997. "Environmental Cleanliness as a Public Good: Welfare and Policy Implications of Nonconvex preferences", J. of Environmental Econ. And Management, 34: 256-274.

Burke, E., 1790 (2009). Reflections on the Revolution in France, Oxford: Oxford Paperbacks, $352 \mathrm{p}$.

Epstein, R. 1992. "Justice across the Generations", in P. Laslett \& J. Fishkin (eds.), Justice between Age Groups and Generations, New Haven \& London: Yale University Press, pp. 84-106.

Casal, P., 2007. "Why Sufficiency Is Not Enough", Ethics, 117: 296-326

Daniels, N., 1988. Am I My Parents' Keeper? An Essay on Justice between the Old and the Young, New York/Oxford: Oxford University Press, 194 p.

Gardiner, S., 2009. “A Contract on Future Generations?” in A. Gosseries \& L. Meyer, Intergenerational Justice, Oxford: Oxford University Press, pp. 77-119.

Gaspart, F. \& A. Gosseries, 2007. “Are Generational Savings Unjust?”, Politics, Philosophy \& Economics, vol. 6 (2): 193-217.

Gauthier, D., 1986. Morals by Agreement, Oxford/New York: Clarendon Press, $367 \mathrm{p}$.

Gosseries, A. , 2004a. Penser la justice entre les générations. De l'affaire Perruche à la réforme des retraites. Paris: Aubier (Flammarion), "Alto" series, $320 \mathrm{p}$. 
2004b. "Historical Emissions and Free-riding", Ethical Perspectives, vol. 11 (1): 36-60.

_ 2008a. "Theories of Intergenerational Justice. A Synopsis", Surv. Perspect. Integr. Environ. Soc. (S.A.P.I.EN.S.), 1(1): 61-71.

2008b. "On Future Generations' Future Rights", J. of Political Philosophy, 16(4): 446-474.

-2008c. "Radiological Protection and Intergenerational Justice", in G. Eggermont \& B. Feltz (eds.), Ethics and Radiological Protection, Louvain-la-Neuve: Academia-Bruylant, pp. 167-195.

_ 2009. "Three Models of Intergenerational Reciprocity", in A. Gosseries \& L. Meyer (eds.), Intergenerational Justice, Oxford: Oxford University Press, pp. 119-146.

Hooker, B., 2005. “The Golden Rule”, Think, 10: 25-29.

Howarth, R., 1992. "Intergenerational Justice and the Chain of Obligation", Environmental Values, Vol. 1(2): 133-140.

Hume, D., 1777 (1994). Political Essays (ed. K. Haakonssen), Cambridge: Cambridge University Press (Cambridge texts in the history of political thought), $416 \mathrm{p}$.

Jaurès, J. 1902. Etudes socialistes, Paris: P. Ollendorf (retrieved in april 2008 from Gallica.bnf.fr).

Masson, A., 1999. “Quelle solidarité intergénérationnelle ?”, Revue française d'économie, vol.14 (1): 27-90.

Mauss, M., 1969. Essais de sociologie, Paris: Minuit ("Points - Sciences humaines" series), $252 \mathrm{p}$.

Parfit, D., 1984. Reasons and Persons, Oxford: Clarendon Press, 564 p.

2010 (forth.). On What Matters, Oxford: Oxford University Press.

Plato, 1997 (ed. J. M. Cooper). Complete works, Indianapolis-Cambridge: Hackett, 1808 p.

Rawls, J., 1999. A Theory of Justice (Revised edition), Oxford/New York: Oxford University Press, $538 \mathrm{p}$.

- 2001. Justice as Fairness: A Restatement (E. Kelly, ed.), Cambridge (Mass.): Harvard University Press, 214 p.

Van Parijs, Ph., 1991. Qu'est-ce qu'une société juste? Introduction à la pratique de la philosophie politique, Paris: Seuil, 312p.

Wade-Benzoni K. A., 2002. " A Golden Rule Over Time: Reciprocity in Intergenerational Allocation Decisions ", Academy of Management Journal, vol. 45(5): 1011-1028.

WCED (World Commission on the Environment and Development), 1987. Our Common Future, Oxford/New York: Oxford University Press. 